\title{
Efficacy of Using a Laser Device to Reduce Wild (Water)Birds Visits to the Free-range area of a Layer Farm Situated in an Avian Influenza Hotspot-region in the Netherlands
}

Armin Elbers ( $\nabla$ armin.elbers@wur.nl )

Wageningen University \& Research

Jose Gonzales

Wageningen University \& Research

\section{Research Article}

Keywords: laser, Mallards, avian repellent, hazing, wild birds, avian influenza, control

Posted Date: January 25th, 2021

DOI: https://doi.org/10.21203/rs.3.rs-149298/v1

License: (c) (i) This work is licensed under a Creative Commons Attribution 4.0 International License. Read Full License 


\section{Abstract}

Free-range layer farms have a significantly higher risk of introduction of avian influenza viruses (AIV) compared to indoor layer farms. Wild water birds, natural reservoir of AIV, likely play a role in the transmission of AIV to chickens by contaminating the farms' free-range area. The use of a laser as a repellent device for wild birds has been studied since the 1970s, in particular around airfields as bird-strike prevention, but its use at poultry farms to keep wild birds away from the surroundings of the poultry barn has not been studied. Part (1.5 ha) of the free-range area of a layer farm that directly boarded the poultry barn was equipped with a video-camera recording system. Visits of wild birds to this free-range study area were recorded for a month without and subsequently a month with a Class-III B laser in operation in the winter period. The laser was operated in the free-range study area between 5:00 PM and 10:00 AM, chickens were present in the free-range study area between 10:00 AM and 5:00 PM. The laser was operated in surrounding grass pastures between 10:00 AM and 5:00 PM. Mallards (Anas platyrhynchos) and Western barn owls (Tyto alba) visited the free-range study area between sunset and sunrise; Blackbirds (Turdus merula), Western yellow wagtails (Motacilla flava), White wagtails (Motacilla alba), Common Moor-hen (Gallimula chloropus) and Common kestrels (Falco tinnunculus) visited the free-range study area between sunrise and 10:00 AM. The overall (all bird species) efficacy of the laser for reducing the rate of wild birds visiting the free-range study area was $98.2 \%$. This efficacy was for birds of the Order Anseriformes $99.7 \%$ and for birds of the Order Passeriformes $96.1 \%$. The overall exposure time of the free-range study area to wild birds (all species) was 617 times lower with the laser in operation compared to a situation in which the laser was not in operation. Exposure time to wild birds of the Order Anseriformes - known as bird flu risk species - was 2,320 times lower compared to the situation without the laser in operation. Summarizing, it can be concluded that the laser equipment used in this study was highly proficient in keeping wild birds - in particular wild ducks - away from the free-range study area of the layer farm.

\section{Introduction}

Wild birds are the natural reservoir of low pathogenic avian influenza viruses (LPAIV), and wild birds are implicated in the dissemination of both LPAIV and highly pathogenic avian influenza viruses (HPAIV) ${ }^{1,2}$ over longer distances. Surveillance studies in birds of the orders Anseriformes (several species of swans, wild ducks and geese) and Charadriiformes (several species of waders, gulls and terns) indicate high LPAIV prevalence. Especially dabbling ducks show high LPAIV seroprevalence $^{3-8}$. Therefore, several wild bird species of these orders are considered AIV high-risk species ${ }^{5,9,10 .}$

A significantly higher risk of introduction of LPAIV and HPAIV is observed for free-range layer farms in comparison to layer farms where the chickens are kept completely inside a poultry barn ${ }^{11-15}$. The majority of LPAIV introductions on Dutch poultry farms is observed on free-range layer farms ${ }^{13,15}$. Wild birds visiting the free-range area may infect chickens by direct contact ${ }^{16}$ or poultry may get infected via indirect contact, like drinking water from water pools formed in the free-range area in the autumn and winter period due to excessive rain, that are contaminated by wild bird faeces ${ }^{17}$. Other indirect contact may be through contact of chickens with droppings from wild birds deposited on the soil in the free-range area ${ }^{18}$.

The use of a laser (an acronym for Light Amplification by Stimulated Emission of Radiation) as a repellent device for wild birds has been studied since the 1970s, in first instance as bird-strike prevention ${ }^{19}$. Bird-strikes, collisions between an aircraft and one or more wild birds, were a prominent reason to look for methods and strategies to avoid wild bird presence at

airfields ${ }^{20-22}$. Later on, lasers were used and evaluated for dispersing wild birds causing agricultural crop damage ${ }^{23,24}$ and resolving human health and safety issues and nuisance problems at landfills, oil-rig platforms and recreational parks ${ }^{25-29}$. birds perceive the approaching laser beam on the ground as a physical danger and as a reaction leave and avoid the area. For wild birds that are active during dusk and night, like wild ducks, of which their eyes are adjusted to vision under dark conditions ${ }^{30}$, it was shown that in particular mallards (Anas platyrhynchos) strongly reacted on a laser by showing avoidance behavior $^{31}$. 
Visits of wild birds to the free-range area of a layer farm were investigated recently using surveillance by a video-camera recording system (VCRS) ${ }^{32}$. Several species of gulls visited the free-range area almost daily from sunrise until 10:00AM between January and August. Mallards (Anas platyrhynchos) predominantly visited the free-range area from sundown till dawn in the period December - February. The investigation revealed no direct contact between the layers and wild birds in the free-range area. In addition, nearly all wild birds disappeared from the free-range area when the layers appeared from the poultry barn in the morning. Take-up of AIV by outdoor layers via water or soil in the free-range area, contaminated by wild bird droppings, was suggested as the most important route of transmission.

Reducing visits of wild birds to the free-range area seems to be a logic preventive measure in order to limit access of chickens to possibly contaminated soil and water. To our knowledge, the use of a laser device in poultry farming to reduce wild bird visits has not been tested in a scientific setting yet. Hence, the objective of our study was to determine the efficacy of a laser device to reduce wild (water)bird visits to the free-range area of a layer farm situated in an avian influenza hotspot-region in the Netherlands.

\section{Material And Methods}

\subsection{Free-range layer study farm}

The free-range layer farm was selected in an earlier study ${ }^{32}$ to investigate visits of wild fauna to the free-range study area using a VCRS. Our study farm experienced several LPAIV introductions in the last 12 years since start of production. As standard procedure for all free-range layer farms in the Netherlands, serological surveillance is performed every three months for presence of AIV antibodies within the national serological surveillance program ${ }^{15}$. About 38,000 laying hens are present at the start of egg production, housed during the night in a barn measuring approximately $120 \mathrm{~m}$ length $\times 40 \mathrm{~m}$ wide. According to regulation ${ }^{33}$, chickens have at least $4 \mathrm{~m}^{2}$ per chicken space in the total free range area. The part of the free-range area that is directly connected to the poultry barn (size: approximately $1.5 \mathrm{ha}$ ) is fenced except for the large right side of that area. In this part of the free-range area (Fig. 1), a video-camera recording system (VCRS) was installed to monitor wild bird visits (we refer in the rest of the manuscript to this area as the free-range study area). Although a large open connection to the grass pastures surrounding the free-range study area exists, no layers would be found in the connecting grass pastures. This is not an unusual situation: in flocks of free-range layers, generally only a small proportion of the flock uses the free-range area at any one time, and in addition often with a very skewed distribution across the free-range area, with the majority of the poultry going outside remaining in the area immediately outside and close to the poultry barn ${ }^{34-36}$. Layers can access the free-range study area through pop holes in the side-wall of the barn.

In the free-range study area, a total of 22 willow trees were present, providing cover, shade and shelter from weather or predators. The private house of the poultry farmer, close to the poultry barn, is surrounded by some large trees. In the freerange area, several waterway ditches (about $1 \mathrm{~m}$ wide, filled with water) are present, which are connected to wider waterways (see Fig. 1). In general but depending on weather conditions and season, the free-range area is made available to the layers mostly from 10:00 AM until sundown. The layers were never fed and watered outdoors. A dairy herd (60 dairy cows and 60 young stock) and 50 sheep are also part of the responsibility of the farmer.

\subsection{Video-camera recording system (VCRS)}

The free-range study area was equipped with a total of eight Hikvision low light Turret 4Mp video-camera's fitted with a fixed focus wide-angle 2.8mm lens (Hikvision, Hangzhou, China; www.hikvision.com) at a height of $4 \mathrm{~m}$ above ground-level on poles (Fig. 2). It was practically impossible to also have VCRS available in the grass pastures, adjacent to the free-range study area, at hundreds of meters away from the poultry barn. Experience with the effect of the laser on wild bird visits in the grass pastures was anecdotal by daily observations of the poultry farmer. 
Video cameras were connected to a TruVision NVR10 network video recorder with HDMI/VGA video-output and a $12 \mathrm{~Tb}$ hard disk for storage (Interlogix, United Technologies Corporated, NC, USA; www.interlogix.com/truvision). The cameras were equipped with IR LEDs enabling night-recording. Recording was done at a speed of 2 frames/s. Video recording covered the time the laser was operating in the free-range study area.

\subsection{Laser equipment and application}

We used an automated laser (Laser Class-III B), Avix Autonomic Mark II (www.birdcontrolgroup.com, Delft, The Netherlands) for this study. The laser was placed on a steel, three-legged tower (the top was $6 \mathrm{~m}$ above ground level) that was secured to a concrete slab $(1.5 \mathrm{~m} \times 1.5 \mathrm{~m})$ weighing approximately $2,000 \mathrm{~kg}$ (Fig. 3$)$. The laser was positioned in the right upper corner of the free-range study area (Fig. 4). It uses a laser with a wavelength of $532 \mathrm{~nm}$ (green color), and has a variable power of 50$499 \mathrm{~mW}$ (depending on installation preference). Studies of the avian retina indicate that birds have a spectral sensitivity range of approximately $300-700 \mathrm{~nm}^{37}$. In general, A Class-III B laser is not capable of creating hazardous diffuse reflection except for conditions of intentional staring into the laser beam at distances close to the diffuser ${ }^{38}$. By regulation, the use of the laser is limited to the property of the farmer, and the laser beam is not allowed to shine on public roads and houses/buildings of neighbors. Sign boards should be put out at the boarders of the property, warning the general public: "Class-III B laser controlled area - avoid eye or skin exposure to direct or scattered radiation". Safety requirements to be met by European standards for consumer laser products are laid down in European Directives 2001/95/EC, 2006/25/EC and 2014/59/EC.

The laser has a horizontal projection range of $360^{\circ}$ (continuous), and a vertical projection range of $-50^{\circ}$ to $+30^{\circ}$. According to the manufacturer, the laser beam can shine $100 \mathrm{~m}$ away for every meter the laser is placed above ground level. The movement of the laser beam over the ground is guided by a small computer, which is part of the laser; the laser-movement navigator is computer-programmed, by manual-visual selection of geographical waypoints in the landscape; the laser beam moves from programmed waypoint to waypoint.

The free-range study area was split into two parts, which were laser-beamed separately (one part laser-beamed in 3:30 min., the remaining other part in 5:30 min.), with an interval of $1 \mathrm{~min}$. without laser-beaming between the two parts. The free-range study area was laser-beamed between approximately 5:00 PM in the evening - depending on changing length of daylight over time- (just after the chickens went inside the poultry barn by themselves due to arrival of sunset) until 10:00 AM the following morning, the time the chickens would be allowed from the poultry barn into the free-range area by the farmer. The grass pastures - approximately up to a distance of $600 \mathrm{~m}$ from the laser - were laser-beamed between 10:00 AM in the morning and approximately 5:00 PM in the evening.

The total surface of the grass pastures was divided into 10 separate parts, that were laser-beamed separately, with an interval of $1 \mathrm{~min}$. A total cycle to laser-beam the different parts took approximately 45 minutes. We choose not to laser-beam the grass pastures also during the night period because it would leave the free-range study area for a large period of time without laser-coverage.

\subsection{Presence of wild birds in surroundings}

In waterways and grass pastures surrounding the free-range study area, flocks of several different wild birds species can be observed in the autumn-winter period: barnacle goose (Branta leucopsis), greater white-fronted goose (Anser albifrons), greyleg goose (Anser anser), mute swans (Cygnus olor), Eurasian wigeons (Mareca penelope), mallards (Anas platyrhynchos), black-headed gull (Chroicocephalus ridibundus), lesser black-backed gull (Larus fuscus), cormorant (Phalacrocorax carbo) and oyster catcher (Haematopus ostralegus) ${ }^{32}$. The free-range layer study farm is located at close distance to the coast in the northern part of the Netherlands. This region is known for wild waterfowl flying along the coast during migration in the Autumn, Winter and Spring time.

\subsection{Translating video recordings into data for analysis}


Video recordings were replayed using the video-recorder with hard-disk storage, as done in an earlier investigation ${ }^{32}$. Features of wild bird visits and operation of the laser were entered into a database: observation date; laser in operation in the freerange area or not; identity of visiting wild bird(s) (Family, Order, Species); time (hh:mm:ss) wild bird(s) start presence in the free-range study area; time (hh:mm:ss) wild bird(s) end presence in the free-range study area; the total number of wild birds in the wild bird visit.

An unique wild bird visit was defined as one or more of wild birds from the same species landing in -or sitting on the fence of - the free-range study area, and subsequently remaining until departing the free-range study area ${ }^{32}$. Wild birds visiting the free-range study area per observation day was defined as the sum of wild birds in wild bird visits per observation day. Exposure time - per observational day - of the free-range area to wild birds, which is the total time wild bird(s) visit the freerange study area per observation day, was calculated as the number of wild birds of the same species, multiplied by the total time of this wild bird visit.

\subsection{Study design}

The manufacturer of the laser equipment claims that the laser is able to decrease wild bird visits for $75 \%$ or more. The field data from the earlier study ${ }^{32}$ indicated that we could expect on average 8 wild ducks visiting per day (standard deviation: 10 duck visits) in the period November - February (situation without the use of the laser). With $95 \%$ confidence and $80 \%$ power and the above-mentioned expectations, the calculated minimum sample size (number of observation days) needed to test the efficacy of the laser to keep wild birds - in particular wild ducks - out of the free range study area, is 24 days with and 24 days without the use of a laser ${ }^{39}$. The study design was as follows: start with approximately one month of video-camera monitoring of wild bird visits without the use of the laser (December 2019; sunset was depending on the observation day between 4:28 PM and 4:35 PM; sunrise was between 8:21 AM and 8:48 AM), followed by one month of observations with the use of the laser (January 2020; sunset was between 4:35 PM and 5:25 PM; sunrise was between 7:52 AM and 8:48 AM). We choose the months of December and January because our previous study in this farm ${ }^{32}$ showed that not only these were the months of peak number of daily visits of birds of the Order Anseriformes but also there was no differences in the average/median number of birds visiting between these two months, hence we would expect a negligible to very low influence of natural temporal changes in the number of birds visiting: eg. reduction of birds visiting in January, which could not be attributed to the presence of the laser.

\subsection{Observer agreement}

Two observers converted the video-data into analyzable data. The identification of wildlife species was conducted by the observers, and if needed with support of a wild bird field guide of Europe ${ }^{40}$ and if needed by a colleague, who has had many years of experience with field identification of birds. If exact species determination was not possible from the video recordings, the general species category was indicated with the addition of an unspecified mark. Inter-observer agreement in observations of wild birds as a measure of data quality was calculated using the Cohen's Kappa statistic ${ }^{41}$ by having pairs of observers independently noting visits of wild birds for the same observation days. Cohen's Kappa was calculated for a) observations on a given night of the visits of wild ducks, which are considered Al risk birds; b) observations on other wild birds (e.g. song birds) that would possibly appear between sunrise and 10:00 AM in the morning after which the chickens would enter the free-range study area. Based on an a priori estimated inter-observer agreement of approximately 0.95 and a maximum acceptable error in the estimated inter-observer agreement of 0.10 and a $95 \%$ confidence level, a sample size of approximately 16 observation days is required ${ }^{39}$.

\subsection{Statistical analysis}

To assess efficacy, the rate of wild birds visiting per observation day was compared between the period with and without the laser in operation on the free-range area of the layer farm. To estimate these rates and compare them, a negative binomial regression model was fitted, which corrected for overdispersion observed when fitting a Poisson regression model ${ }^{42}$. Two models were fitted, the first model aimed to compare the overall rate of wild birds visiting between periods with and without 
the laser in operation. In this model the response variable were the total number of birds visiting per observation day and the explanatory variable was a variable identifying the presence or absence of the laser. The exponent of the estimated regression coefficient of this model is the relative risk (RR) of birds visiting the free-range when the laser was present.

The second model fitted used as explanatory variables the taxonomic Order of the birds visiting and the interaction with the variable identifying the presence/absence of the laser. The exponent of the bird order:Laser-presence interaction represents the RR of birds from each Order visiting the free-range study area when the laser was present. The threshold for significance of the estimated parameters was $p<0.05$. Next we estimated the percentage efficacy of the Laser for reducing the daily rate of wild birds visiting as: Laser efficacy=(1-RR_Laser)*100.

Comparisons between the period with the laser absent and present were also made on the number of days with observed wild bird visits within each experimental period and the free-range exposure time. Number of days with visits were compared using the Chi-square test and the exposure time was compared by fitting negative binomial regression models using the same approach as that described for assessing the rates of wild birds visiting per day.

All analyses were done using the statistical software R version 4.0.2 (R Development Core Team, 2020).

\section{Results}

\section{Inter-observer agreement}

Mean Cohen's Kappa statistic measuring the inter-observer agreement for observations on mallards was 1.00 (s.d.: 0; range: 1-1) based on 17 observation days. For observations on other wild birds, mean Cohen's Kappa was 0.994 (s.d.: 0.027: range $0.89-1$ ) based on 17 observation days with these birds present. Disagreement was present in only one wild bird observation on a given day where some White wagtails (Motacilla alba) were missed by one of the observers.

\section{General observations}

Mallards ((Anas platyrhynchos) visited the free-range study area without the laser in operation between just after sunset (when the layers were already back into the poultry barn) and sunrise. Western barn owls (Tyto alba) hunted in the free-range study area on mice and rats during the night. Blackbirds (Turdus merula), Western yellow wagtails (Motacilla flava), White wagtails (Motacilla alba), Common Moor-hen (Gallimula chloropus) and Common kestrels (Falco tinnunculus)) visited the free-range study area limited to the period after sunrise in the morning until 10:00 AM without the laser in operation. When the layers would flow out of the poultry barn and into the free-range study area at around 10:00 AM, these wild birds would disappear, scared by the large amount of layers in the free-range study area. It was expected to have a number of gulls of different species present in the free-range study area in the morning between sunrise and 10:00 AM. They were not observed this time, but were seen present in the surrounding pastures in the time period that the laser was operational in the free-range study area and at the same time not sweeping in the surrounding pastures.

Without the laser in operation, mallards (Anas platyrhynchos) visited the free-range study area of the poultry farm on 28 out of 29 observation days, while with the laser in operation, mallards visited the free-range study area on 1 out of 28 observation days (Fig. 5), which is a highly $(p<0.001)$ significant reduction in the number of days mallards visited the free range. Furthermore, without the laser in operation, other birds (Blackbird (Turdus merula), Western yellow wagtail (Motacilla flava), White wagtail (Motacilla alba), Western barn owl (Tyto alba), Common Moor-hen (Gallimula chloropus) and/or Common kestrel (Falco tinnunculus)) visited the free-range study area on 18 out of 29 observation days, while with the laser in operation, other birds visited the free-range study area on 4 out of 28 observation days (Fig. 4), which is a highly $(p<0.001)$ significant reduction in the number of days these wild birds visited the free range area. 


\section{Daily rate of wild birds visiting}

A summary of descriptive statistics on daily rate of wild birds visiting the free range study area with and without the laser in operation, grouped by taxonomic Order, are shown in Table 1. Wild birds of the Order Anseriformes, in this case only mallards (Anas platyrhynchos), visited the free-range study area often and with considerable day-to-day variation in the period without the laser in operation while virtually no mallards were observed in the period with the laser in operation (Fig. 5). A similar effect of the laser can be observed for visiting wild birds of the Orders Passeriformes, Strigiformes, Gruiformes and Falconiformes, although the number of visits are considerably smaller compared to those by the mallards (Fig. 5).

Table 1

Summary of daily number of wild birds visiting during the experimental periods ( 28 observation days with and 29 days without the laser in operation), grouped by taxonomic Order, observed in the free range study area.

\begin{tabular}{|lllll|}
\hline Order & Laser present & Median & Min & Max \\
\hline Anseriformes & No & 10 & 0 & 29 \\
& Yes & 0 & 0 & 1 \\
\hline Passeriformes & No & 4 & 0 & 30 \\
& Yes & 0 & 0 & 4 \\
\hline Falconiformes & No & 0 & 0 & 0 \\
\hline \multirow{2}{*}{ Gruiformes } & Yes & 0 & 0 & 1 \\
\hline \multirow{2}{*}{ Strigiformes } & No & 0 & 0 & 1 \\
\hline & Yes & 0 & 0 & 0 \\
\hline
\end{tabular}

The mean daily rate of wild birds (all species) visiting was significantly $(p<0.001)$ lower when the laser was used: RR = 0.0183 (95\% Cl: $0.007-0.043)$, which means that with the laser in operation, the mean rate of wild birds (all species) visiting is $55(1 / 0.0183)$ times lower than when the laser is not in operation.

\section{Daily rate of wild birds visiting by taxonomic Order}

The mean daily rate of wild birds of the Order Anseriformes visiting the free-range study area was significantly $(p<0.001)$ lower when the laser was used: $\mathrm{RR}=0.00327$ (95\% Cl: 0.00018-0.0159), which means that with the laser in operation, the mean rate of wild birds of the Order Anseriformes visiting was $306(1 / 0.00327)$ times lower than when the laser is not in operation. Furthermore, the mean daily rate of wild birds of the Order Passeriformes visiting was significantly $(p<0.001)$ lower when the laser was used: RR 0.0394 (95\% Cl: 0.0149-0.0919), which means that with the laser in operation, the mean rate of wild birds of the Order Passeriformes visiting was 25 (1/0.0394) times lower than when the laser is not in operation. To estimate the RR for birds of the Orders Falconiformes, Gruiformes and Strigiformes, they were combined into one group because of their low number of daily visits. The mean daily rate of wild birds of the Orders Falconiformes, Gruiformes and Strigiformes together visiting was about 4 times (not significant, $\mathrm{p}=0.22)$ lower when the laser was used: $\mathrm{RR}=0.256(95 \% \mathrm{Cl}$ : 0.0129-1.7689).

A stone marten (Martes foina) family - with a burrow in the middle of the free-range study area - and numerous unspecified species of mice and rats appeared daily during the night in the free-range study area. The laser had no influence whatsoever on the daily rate of visiting by these mammals. 


\section{Laser efficacy}

The estimated RRs were used to calculate the percent efficacy of the laser for reducing the rate of wild birds visiting. The overall (all bird species) efficacy of the laser for reducing the rate of wild birds visiting was $98.2 \%$ (95\% Cl: 95.7-99.3). The estimated efficacy of the laser for reducing the rate of wild birds visiting for each taxonomic Order was: $99.7 \%$ (95\% Cl: 98.499.98) for birds of the Order Anseriformes, $96.1 \%$ (95\% Cl: 90.8-98.5) for the birds of the Order Passeriformes and $74.4 \%$ (95\% Cl: 0-98.7) for birds of the Orders Falconiformes, Gruiformes and Strigiformes together.

\section{Exposure time of free-range study area to wild birds}

A summary of descriptive statistics on exposure time of the free-range study area to visiting wild birds with and without the laser in operation, grouped by taxonomic Order, are shown in Table 2. The overall exposure time (all bird species) was significantly $(p<0.001)$ lower when the laser was used: $R R=0.00162(95 \% \mathrm{Cl}: 0.000295-0.0089)$, which means that with the laser in operation, exposure time was 617 (1/0.00162) times lower than when the laser was not in operation.

Table 2

Summary of daily exposure time (in min.) of free-range study area to wild birds. This is a combination of the number of birds visiting daily and the duration of their visit during the experimental periods ( 28 observation days with and 29 days without the laser in operation), grouped by taxonomic Order.

\begin{tabular}{|lllll|}
\hline Order & Laser present & Median time & Min & Max \\
\hline Anseriformes & No & 2144.21 & 15.80 & 15323.45 \\
& Yes & 1.25 & 1.25 & 1.25 \\
\hline Passeriformes & No & 31.75 & 0.37 & 253.43 \\
& Yes & 4.43 & 1.00 & 5.05 \\
\hline Falconiformes & Yes & 0.45 & 0.45 & 0.45 \\
\hline Gruiformes & No & 1.88 & 1.88 & 1.88 \\
\hline Strigiformes & No & 2.68 & 0.70 & 27.83 \\
\hline
\end{tabular}

Exposure time to wild birds of the Order Anseriformes was significantly $(p<0.001)$ lower when the laser was used: RR = 0.000431 (95\% Cl: 0.0000246-0.00756), which means that with the laser in operation, exposure time of wild birds of the Order Anseriformes was 2,320 (1/0.000431) times lower than when the laser is not in operation. Furthermore, exposure time to wild birds of the Order Passeriformes was significantly $(p<0.001)$ lower when the laser was used: $\mathrm{RR}=0.0575(95 \% \mathrm{Cl}$ : $0.0129-0.2566$ ), which means that with the laser in operation, exposure time of wild birds of the Order Passeriformes was 17 $(1 / 0.0575)$ times lower than when the laser is not in operation.

To estimate the RR with respect to exposure time for birds of the Orders Falconiformes, Gruiformes and Strigiformes, they were combined into one group because of their low number. Exposure time to wild birds of the Orders Falconiformes, Gruiformes and Strigiformes together was 18 times (1/0.0544; not significant, $p=0.14)$ lower when the laser was used: RR = 0.0544 (95\% Cl: 0.00115-1.04175).

\section{Observations by farmer in surrounding pastures}

Since there was no VCRS monitoring in the surrounding pastures, we could only rely on anecdotal daily observations by the poultry farmer. He indicated that without the laser in operation in the pastures, sometimes large congregations of geese (barnacle goose (Branta leucopsis), greyleg goose (Anser anser), greater white-fronted goose (Anser albifrons), gulls (lesser 
black-backed gull (Larus fuscus), black-headed gull (Chroicocephalus ridibundus) and occasionally some swans (mute swan (Cygnus olor)) were observed to be present. With the laser in operation, the pastures were swept clean: no geese, gulls or swans were observed by the poultry farmer anymore during daytime.

\section{Discussion}

The measures of inter-observer agreement in this study are considered perfect ${ }^{41}$ or excellent ${ }^{43}$, indicating the availability of high quality data for a sound scientific analysis.

The objective of our study was to determine the efficacy of a laser device to keep wild birds - in particular wild ducks - out of the free-range study area of a layer farm situated in an avian influenza hotspot-area of the Netherlands. The overall (all bird species) efficacy of the laser for reducing the rate of wild birds visiting was $98.2 \%$. Specifically for birds of the Order Anseriformes the efficacy of the laser for reducing the rate of wild birds visiting was $99.7 \%$, for birds of the Order Passeriformes $96.1 \%$, and for the birds of the Orders Falconiformes, Gruiformes and Strigiformes together, $74.4 \%$ respectively. Given our previous observations in this layer $\mathrm{farm}^{32}$, particularly regarding the expected numbers of daily visits in December and January (see methods), we expect that the estimated efficacies can be mostly attributed to the effect of the laser. The overall exposure time of the free-range study area to wild birds (all species) - a direct measure of potential risk for contamination of the free-range study area - was 617 times lower with the laser in operation compared to a situation in which the laser was not in operation. Specifically, exposure time of the free-range study area to wild birds of the Order Anseriformes - known as bird flu risk species - was 2,320 times lower with compared to without the laser in operation. Summarizing, it can be concluded that the laser equipment used in this study was highly proficient in keeping wild birds - in particular wild ducks - away from the free-range study area of the layer farm.

Most earlier studies investigating the efficacy of a laser in relationship to wild birds were focused on hazing and dispersal, and in majority executed in experiments in small confined rooms with a limited number of captured wild birds and over a limited time period, mostly a few days. Blackwell et al. ${ }^{25}$, using a Class-II B laser, 10-mW power, with $632 \mathrm{~nm}$ wavelength (red color), showed $96 \%$ of Canada geese (Branta canadensis) and $57 \%$ of mallards (Anas platyrhynchos) to be dispersed by the laser. Baxter ${ }^{21}$, using a Lord-Ingerie LEM 50 laser, 5-mW power, with $650 \mathrm{~nm}$ (red color), was able to reduce the number of Black-headed gulls (Larus ridibundus), common gulls ( L. canus), Lesser Black-backed gulls ( $L$. fuscus), Herring gulls ( $L$. argentatus) and Great Black-backed gulls (L. marinus) at reservoirs near airports by $85 \%$. Holevinski et al. ${ }^{27}$, using a Class-II $68-\mathrm{mW}, 650 \mathrm{~nm}$ (red color) laser, were able to remove $>90 \%$ of Canada geese (B. canadensis) in $64 \%$ of hazing events. Glahn et al. ${ }^{44}$, using a Class-II 68-mW, $650 \mathrm{~nm}$ (red color) laser, were able to show during field trials that the laser was consistently effective in reducing cormorant (Phalacrocorax auritus) populations by at least $90 \%$. Furthermore, even after use of the laser in separate trials about a month apart, there was no conspicuous habituation of birds to the laser beams. Werner and Clark ${ }^{45}$, using a Class-II 68-mW, $650 \mathrm{~nm}$ (red color) laser, showed reduction in Canada geese (B. canadensis) occupancy of experimental plots with $>92 \%$. Gorenzel et al. ${ }^{23}$, using a Class-II 68-mW, $650 \mathrm{~nm}$ (red color) laser, showed that laser harassment caused $100 \%$ of American crows (Corvus brachyrhynchos) to leave $49 \%$ of urban roosts immediately, and between $50-99 \%$ of all crows to fly away at $44 \%$ of the laser-beamed roosts. Sherman and Barras 46 , using a handheld ClassIII B, 50-mW, 650-nm (red color) diode laser, were able to reduce Canada geese (B. canadensis) numbers by $85 \%$. Latour and $\mathrm{Stahl}^{24}$ executed a field experiment with a handheld Class-III B laser in the Netherlands to investigate the direct and transient effect of the laser to haze several species of geese: in $91 \%$ of the cases geese would react by moving/flying up and in $67 \%$ of the cases they flew off. In summary most of these studies, using different lasers, reported efficacies higher than $80 \%$, particularly for water birds (geese and gulls). Our study provides field evidence for further confirmation of the reported high efficacies, in particular for mallards. Furthermore, the anecdotal observations of the farmer in the pastures are also an indication of the efficacy of the laser for reducing visits of geese and gulls in those areas.

An important requirement for habituation of wild birds to the presence and operation of the laser is that the stimulus will be repeated and is predictable $e^{47,48}$. Because the laser-beam is moving through the landscape in a seemingly random fashion, its 
predictability for wild birds is probably limited. In the 28 consecutive days that the laser was in operation in our study, we did not observe any possible habituation of wild bird species to the presence and operation of the laser. This is in accordance with other studies $24,25,28,44,45$ although many were of limited length (only a few days).

There is very scarce data concerning health effects and risks for birds by lasers with laser-power equal or larger than the laser used in our study. Glahn et al. ${ }^{44}$ conducted an ocular hazard assessment with a class IIIB laser with a power of $5 \mathrm{~mW}$ (moderate power). Five captive double-crested cormorants (Phalacrocorax auritus) were used for an exposure experiment: the birds were hand-held and their eyes exposed to the laser at a distance of 1,13 and $33 \mathrm{~m}$. Exposure distances were chosen based on the nominal ocular risk distance (NORD) to humans for this specific laser (approximately $13 \mathrm{~m}$ ) with the assumption of an eye-blink reaction time of 0.25 seconds; 24 - and 48-h post-treatment examination of the eyes of the experimental birds revealed no ocular changes at the distances investigated. The manufacturer of the laser indicates that there is virtually no risk of eye damage for the wild birds because birds react strongly on the laser beam that is coming in their direction on the ground and fly away before the laser beam might touch their eyes. In our study, similar to other investigations ${ }^{21,24,27,46}$, wild birds that were dislodged by the laser, settled down in pastures nearby, but outside the area that was laser-beamed. Indirect indications for limited to neglectable ecological damage to wild birds due to the use of a laser can be derived from the fact that after laser activity was stopped in experimental settings, wild birds would return back to the area mostly within one to a couple of days ${ }^{21,23,25,45}$. When we stopped the laser activity after 28 days of operation in our experiment, it took two and six days for wild birds of the Order Passeriformes and Anseriformes, respectively, to show up again in the free-range study area. The number of birds visiting returned to levels comparable to the period before the laser was put into operation in our experiment.

About $20 \%$ of free-range layer farms in the Netherlands have experienced one or more introductions of LPAIV in the period 2007-2018 (Fig. 6). We know so precisely, because the surveillance systems in operation in the Netherlands give us a complete insight into what is happening ${ }^{13,15}$. Close distance to waterways (a proxy for an attractive environment for wild water birds) and close distance to nature reserves with presence of AIV high-risk (water) birds were among the important risk factors for introduction of LPAIV on free-range layer farms ${ }^{15}$. So, for a limited number of free-range layer farms, situated in AIV high-risk areas and with a history of (recurrent) LPAIV introductions, the use of a laser might be helpful as preventive measure to keep wild water birds away from the free-range area of the layer farms.

There may be ecological implications for the mass application of these lasers by other poultry production type farms, these implications may need to be assessed before a recommendation of mass application is made. For now given both 1) the high risk of HPAIV introductions from wild water birds contaminating the area around poultry farms being experienced yearly since $2014^{49}$, and 2) the efficacy of the laser to reduce wild bird visits, it could be considered the use of the laser as a preventive measure in AIV hot-spot farms, similar to the one of this study.

In conclusion, in this study we confirm the high efficacy of using lasers to reduce the daily number of wild bird visits to the free-range area of a layer farm situated in a AIV-hotspot area. Given this high efficacy, the application of these lasers becomes a viable alternative for the prevention of introduction of avian influenza infections in poultry.

\section{Declarations}

\section{Acknowledgments}

Iris Pronk (student of InHolland University of Applied Sciences, Delft) is acknowledged for helping out during practical work at the study farm and with converting part of the video recordings into analyzable data. Kees Veldman (Wageningen Bioveterinary Research) is thanked for helping with the identification of wild bird species. The poultry farmer is gratefully acknowledged for cooperation and giving access to his poultry farm. This work was part of the research project Fight Flu (project \# TKI-AF-15225) which was funded by the Dutch Ministry of Agriculture, Nature and Food Quality and by AVINED 
(coordinating representative for the poultry industry) within the public-private partnership "1Health4Food" in The Netherlands (https://www.1health4food.nl).

\section{Author Contributions}

A.R.W.E. devised the study, was responsible for funding acquisition, gathered the data, helped implement the methods and drafted the manuscript. J.L.G. implemented the methods, analyzed the data and helped drafting the manuscript. Both authors read and approved the final manuscript.

\section{Competing Interests}

The authors declare to have no competing interests.

\section{References}

1. Gilbert, M. et al. Anatidae migration in the western Palearctic and spread of highly pathogenic avian influenza H5N1 virus. Infect. Dis.12, 1650-1656. (2006).

2. Verhagen, J.H., Herfst, S. \& Fouchier, R.A.M. How a virus travels the world. Science 347, 616-617 (2015).

3. Stallknecht, D.E. \& Shane, S.M. Host range of avian influenza virus in free-living birds. Res. Commun.12, 125-141 (1998).

4. Olsen, B. et al. Global Patterns of Influenza A Virus in Wild Birds. Science312, 384-388 (2006).

5. Munster, V.J. et al. Spatial, temporal, and species variation in prevalence of influenza A viruses in wild migratory birds. PLoS Pathog.3, e61 (2007).

6. Haynes, L. et al. Australian surveillance for avian influenza viruses in wild birds between July 2005 and June 2007. Vet. J.87, 266-272 (2009).

7. N.S. et al. Avian Influenza virus surveillance in wild birds in Georgia: 2009-2011. PLoS ONE8(3), e58534 (2013).

8. Grillo, V.L. et al. Avian influenza in Australia: a summary of 5 years of wild bird surveillance. Vet. J.93, 387-393 (2015).

9. Veen, J. et al. Ornithological data relevant to the spread of Avian Influenza in Europe: further identification and first assessment of higher risk species. Wetlands International, Wageningen, The Netherlands. 60 pp. (2007).

10. European Food Safety Authority (EFSA). Avian influenza overview September - November 2017. EFSA Journal, 15, e05141 (2017).

11. Terregino, C. et al. Active surveillance for avian influenza viruses in wild birds and backyard flocks in Northern Italy during 2004 to 2006. Avian Pathol.36, 337-344 (2007).

12. Welby, S. et al. Redesigning the serological surveillance program for notifiable avian influenza in Belgian professional poultry holdings. Avian Dis. 54 (Suppl. 1), 597-605 (2010).

13. Gonzales, J.L., Stegeman, J.A., Koch, G., de Wit, J.J., \& Elbers, A.R.W. Rate of introduction of a low pathogenic avian influenza virus infection in different poultry production sectors in the Netherlands. Influenza other respir. viruses7, 6-10 (2013).

14. Kirunda, H. et al. Seroprevalence and risk factors for exposure of free-range poultry to avian influenza viruses in important bird areas in Uganda. Avian Dis. 59, 64-70 (2015).

15. Bouwstra, R. et al. Risk for Low Pathogenicity Avian Influenza Virus on Poultry Farms, the Netherlands, 2007-2013. Infect. Dis. 23, 1510-1516 (2017).

16. Alexander, D.J. An overview of the epidemiology of avian influenza. Vaccine 25, 5637-5644 (2007).

17. Markwell, D.D. \& Shortridge, K.F. Possible Waterborne transmission and maintenance of influenza viruses in domestic ducks. Environ. Microbiol. 43, 110-115 (1982). 
18. von Waldburg-Zeil, C.G., van Staaveren, N. \& Harlander-Matauschek, A. Do laying hens eat and forage in excreta from other hens? Animal 13(2), 367-373 (2019).

19. Short, J.J., Kelley, M.E., Speelman, R.J. \& McCarty, R.E. Birdstrike prevention: applying aero-science and bio-science. 25th International Bird Strike Committee, Amsterdam, The Netherlands, 17-21 April 2000.

https://worldbirdstrike.com/IBSC/Amsterdam/IBSC25\%20WPRS4.pdf.

20. Australian Transport Safety Bureau (ATSB). The hazard posed to aircraft by birds. 48 pp. (2003).

https://www.atsb.gov.au/media/43383/Hazard_aircraft_by_birds.pdf

21. Baxter, A. Laser dispersal of gulls from reservoirs near airports. 2007 Bird strike committee USA/Canada, $9^{\text {th }}$ Annual meeting, Kingston, Ontario (2007). https://digitalcommons.unl.edu/birdstrike2007/2.

22. Foss, C.R., Ronning, D.J. \& Merker, D.A. Intense short-wavelength light triggers avoidance response by Red-tailed Hawks: a new tool for raptor diversion? The Condor: ornithological applications119, 431-438 (2017).

https://doi.org/10.1650/CONDOR-16-230.1.

23. Gorenzel, W.P., Blackwell, B.F., Simmons, G.D., Salmon, T.P. \& Dolbeer, R.A.. Evaluation of lasers to disperse American crows (Corvus brachyrhynchos) from urban night roosts. J. Pest Manag. 48, 327-331 (2002).

24. Latour, J.B. \& Stahl, J. Field investigation: use of lasers to limit damage by geese. A\&W-rapport 2388, Sovon rapport 2018/08 (in Dutch). 83pp.

25. Blackwell, B.F., Bernhardt, G.E. \& Dolbeer, R.A. Lasers as nonlethal avian repellents. Wildlife Manag.66, 250-258 (2002).

26. Gilsdorf, J.M., Hygnstrom, S.E. \& VerCauteren, K.C. Use of frightening devices in wildlife damage management. Integrated Pest Manag. Rev.7, 29-45 (2002).

27. Holevinski, R.A., Curtis, P.D. \& Malecki, R.A. Hazing of Canada geese is unlikely to reduce nuisance populations in urban and suburban communities. Human-Wildlife Conflicts1, 257-264 (2007).

28. Gorenzel, W.P., Salmon, T.P. \& Imai, R. Response of water birds to hazing with a red laser. Proc. $24^{\text {th }}$ Pest Conf. (eds. R.M. Timm and K.A. Fagerstone), pp. 235-240 (2010). https://escholarship.org/uc/item/33z6p0fm.

29. Brown, R. Laser scarecrows: gimmick or solutions ? University of Rhode Island Vegetable Production Research Reports. Paper 25 (2017). http://digitalcommons.uri.edu/riaes_bulletin/25.

30. Sillman, A. Avian vision. In Avian Biology, vol. 3. Eds. D.S. Farner, J.R. King, K.C. Parkes. Academic Press, New York, U.S.A. : 349-387 (1973).

31. Lustick, S.I. The effect of intense light on bird behavior and physiology. Bird control Seminar Proceedings. 119; 171-186 (1973). http://digitalcommons.unl.edu/icdwmbirdcontrol/119.

32. Elbers, A.R.W. \& Gonzales, J.L. Quantification of visits of wild fauna to a commercial free-range layer farm in the Netherlands located in an avian influenza hot-spot area assessed by video-camera monitoring. Emerg. Dis.67, 661-677 (2019).

33. KAT - Verein für kontrollierte alternative Tierhaltungsformen e.V. KAT-handleiding legbedrijven, Versie 1 - april 2017 / Nr. 2017.01.

https://www.verbeek.nl/download/829/Downloads/NL/Actueel/2017_01_24_KAT_handleiding_legbedrijven_2017.01.pdf

34. Hughes, B.O. \& Dun, P. Production and behaviour of laying domestic fowls in outside pens. Anim. Product.11, 201 (1983).

35. Zeltner, E. \& Hirt, H. Effect of artificial structuring on the use of laying hen runs in a free-range system. Poultry Sci.44, 533537 (2003).

36. Singh, M. \& Cowieson, A.J. Range use and pasture consumption in free-range poultry production. Product. Sci.53, 12021208 (2013).

37. Bennett, A.T.D. \& Thery, M. Avian Color Vision and Coloration: Multidisciplinary Evolutionary Biology. American Naturalist169 (suppl.), S1-S6 (2007).

38. Occupational Safety and Health Administration (OSHA). Guidelines for laser safety and hazard assessment. Directives PUB 8-1.7 (1991). OSHA, Washington, D.C., U.S.A. 
39. Abramson, J.H. WINPEPI (PEPI-for-Windows): computer programs for epidemiologists. Epidemiologic Perspectives and Innovations1, 6 (2004).

40. Svensson, L., Mullarney, K., \& Zetterström, D. Vogelgids van Europa, 5th Edition. Dutch translation of “Fågelguiden Europas och Medelhavsområdets fågler i fält", Vogelbescherming Nederland en ANWB. Tirion Uitgevers, Utrecht, The Netherlands. 447 pp. (2012).

41. Landis, J.R. \& Koch, G.G. The measurement of observer agreement for categorical data. Biometrics 33, 159-174 (1977).

42. R Core Team. R: A language and environment for statistical computing. R Foundation for Statistical Computing, Vienna, Austria (2020). https://www.R-project.org/.

43. Fleiss, J. L.. Statistical methods for rates and proportions. 2nd ed. (New York: John Wiley) pp. 38-46 (1981).

44. Glahn, J.F., Ellis, G. \& Fioranelli, P., Dorr, B.S. Evaluation of moderate and low-powered lasers for dispersing double-crested cormorants from their night roosts. Wildlife damage management Conferences- Proceedings, 11 (2000). http://digitalcommons.unl.edu/icwdm_wdmconfproc/11.

45. Werner, J.T. \& Clark, L. Effectiveness of a motion-activated laser hazing system for repelling captive Canada geese. Soc. Bull.34, 2-7 (2006).

46. Sherman, D.E. \& Barras, A.E. Efficacy of a laser device for hazing Canada geese from urban areas of Northeast Ohio. Ohio J. Sci.104, 38-42 (2004).

47. Madsen, J. Experimental refuges for migratory waterfowl in Danish wetlands. I. Baseline assessment of the disturbance effects of recreational activities. Appl. Ecol.35: 386-397 (1998).

48. Bechet, A., Giroux, J-F. \& Gauthier, G. The effects of disturbance on behaviour, habitat use and energy of spring staging snow geese. Appl. Ecol.41: 689-700 (2004).

49. Adlhoch, C. et al. Scientific report: Avian influenza overview August - December 2020. EFSA Journa/18(12):6379 (2020).

\section{Figures}

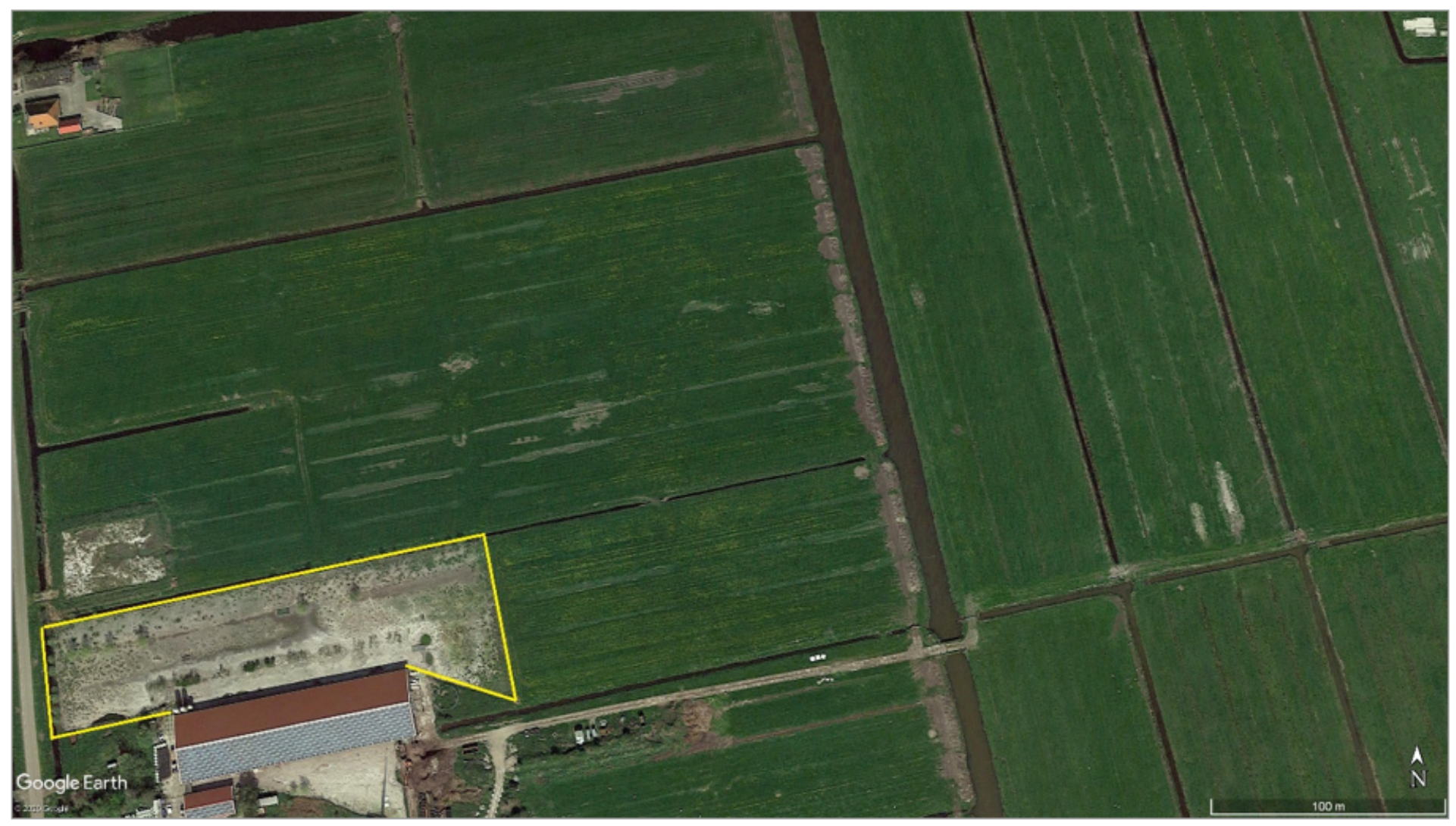




\section{Figure 1}

Aerial view of the layer farm, with the free-range study area directly connected to the poultry barn (inside the yellow line), and the surrounding grass pastures that formed the total surface of the free-range area (source: Google Earth Pro, 2020).

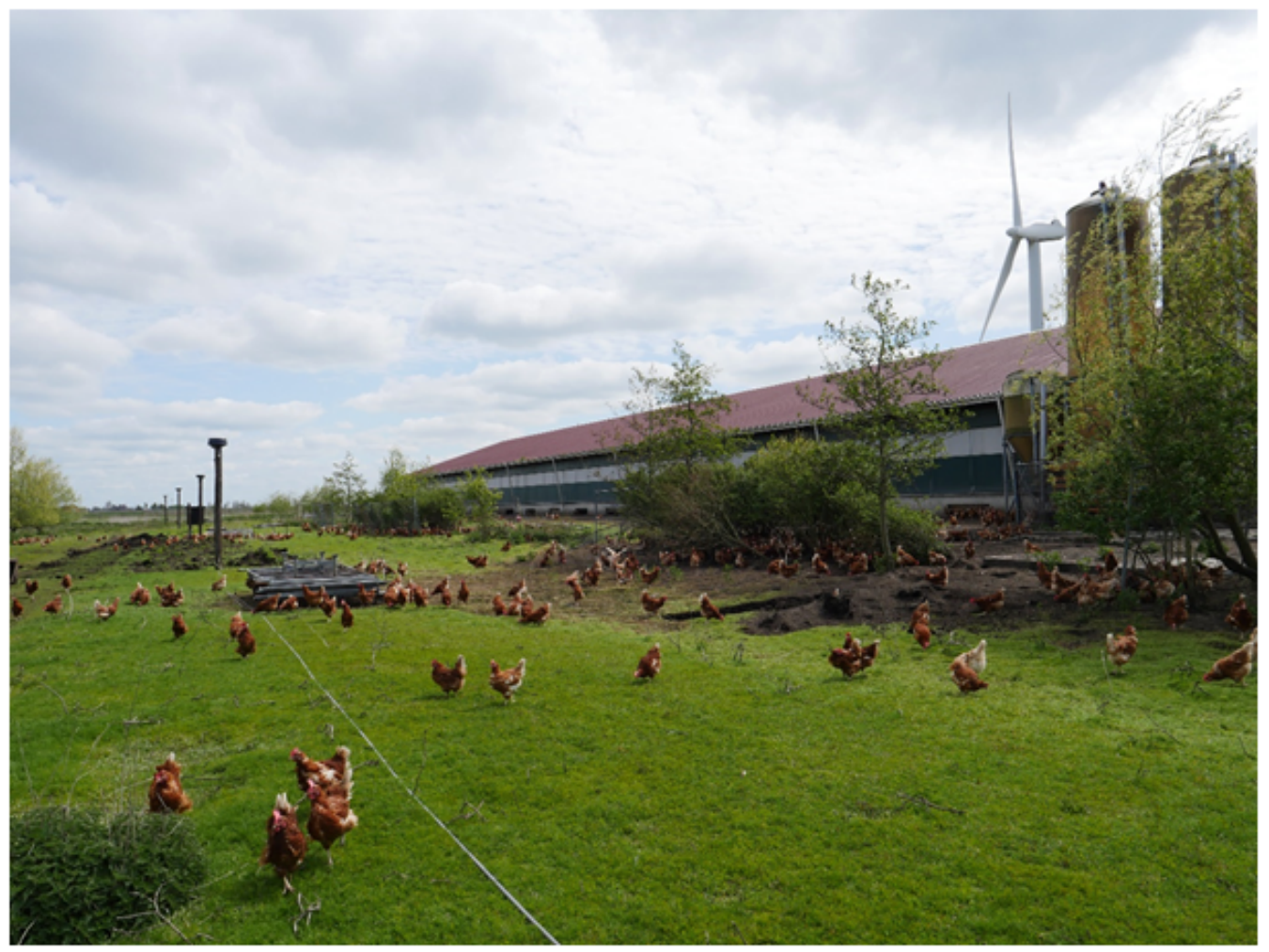

\section{Figure 2}

Wide-angle video-cameras installed at a height of approximately $4 \mathrm{~m}$ above ground-level on poles in the free-range study area.

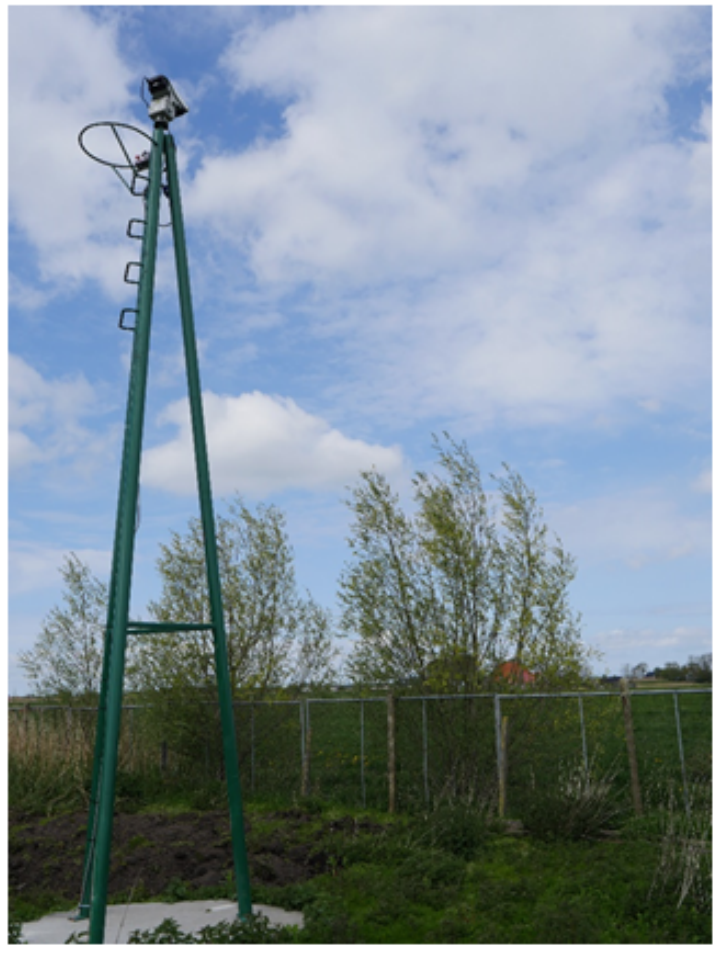




\section{Figure 3}

The laser placed on a steel, three-legged tower (the top was $6 \mathrm{~m}$ above ground level) that was secured to a concrete slab $(1.5 \mathrm{~m} \times 1.5 \mathrm{~m})$ weighing approximately $2,000 \mathrm{~kg}$.

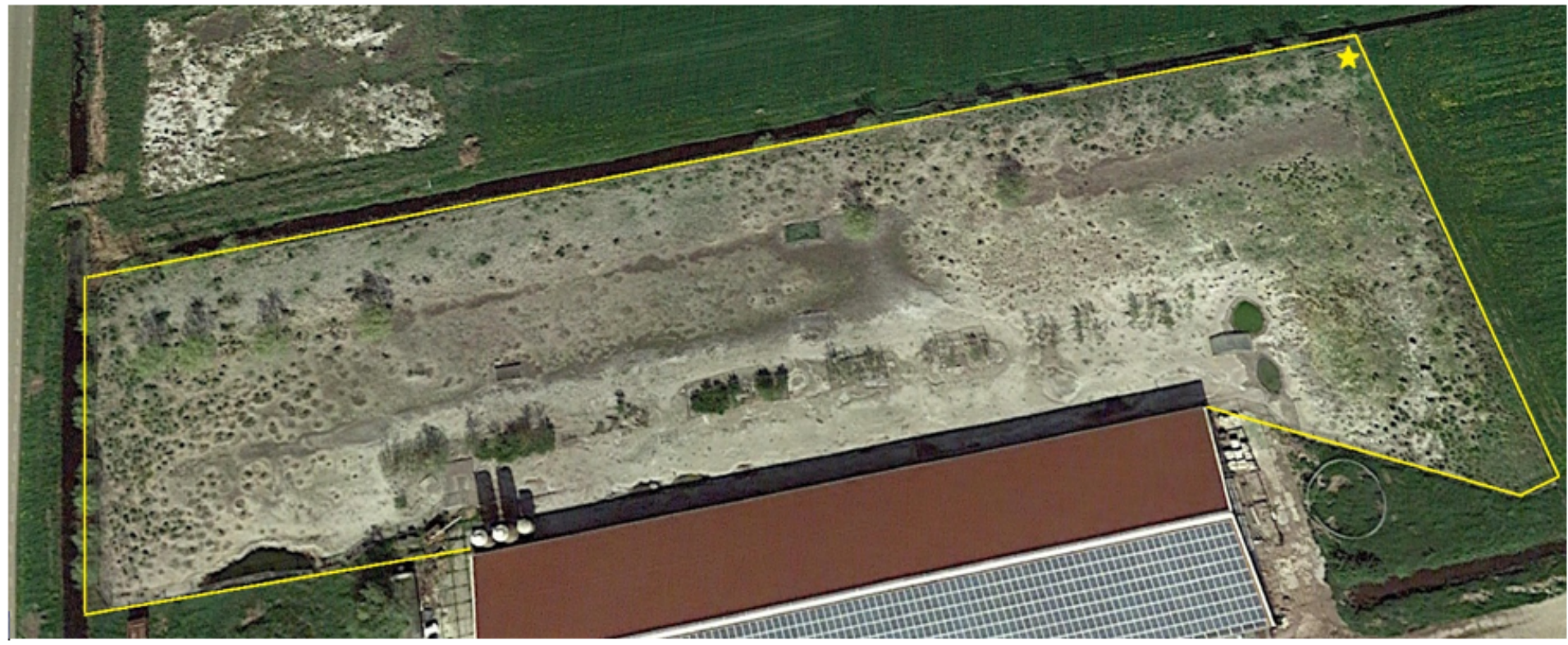

\section{Figure 4}

Aerial view of the free-range study area (within yellow borderline) with placement of the laser in the upper right corner (yellow star) (Source: Google Earth Pro, 2020). 

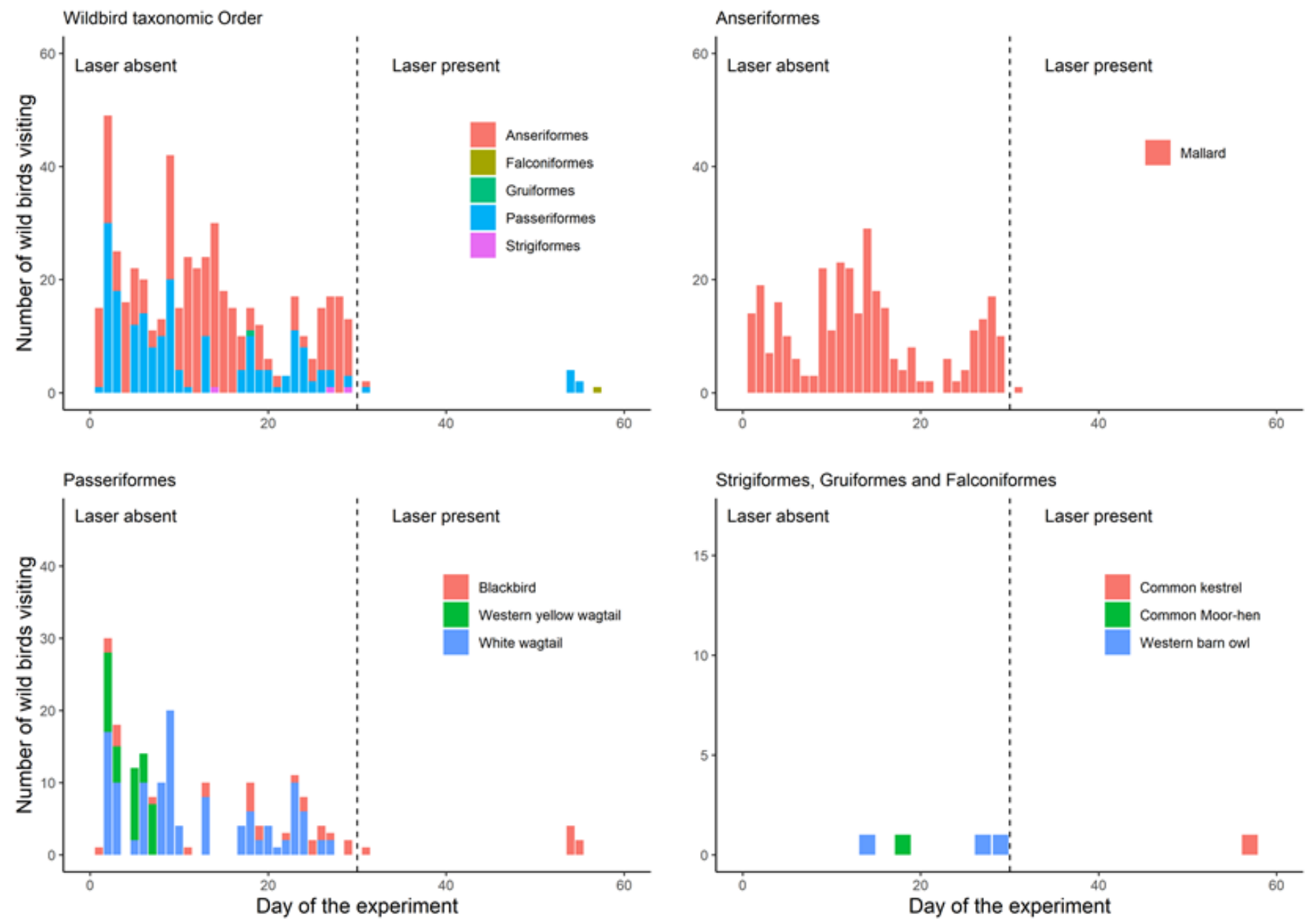

\section{Figure 5}

Number of wild birds visiting the free-range study area of the layer farm by observation day with and without the laser in operation; for all wild bird species together (upper left corner); for wild birds of the order Anseriformes (upper right corner); for wild birds of the order Passeriformes (lower left corner); for wild birds of the order Strigiformes, Gruiformes and Falconiformes (lower right corner). 


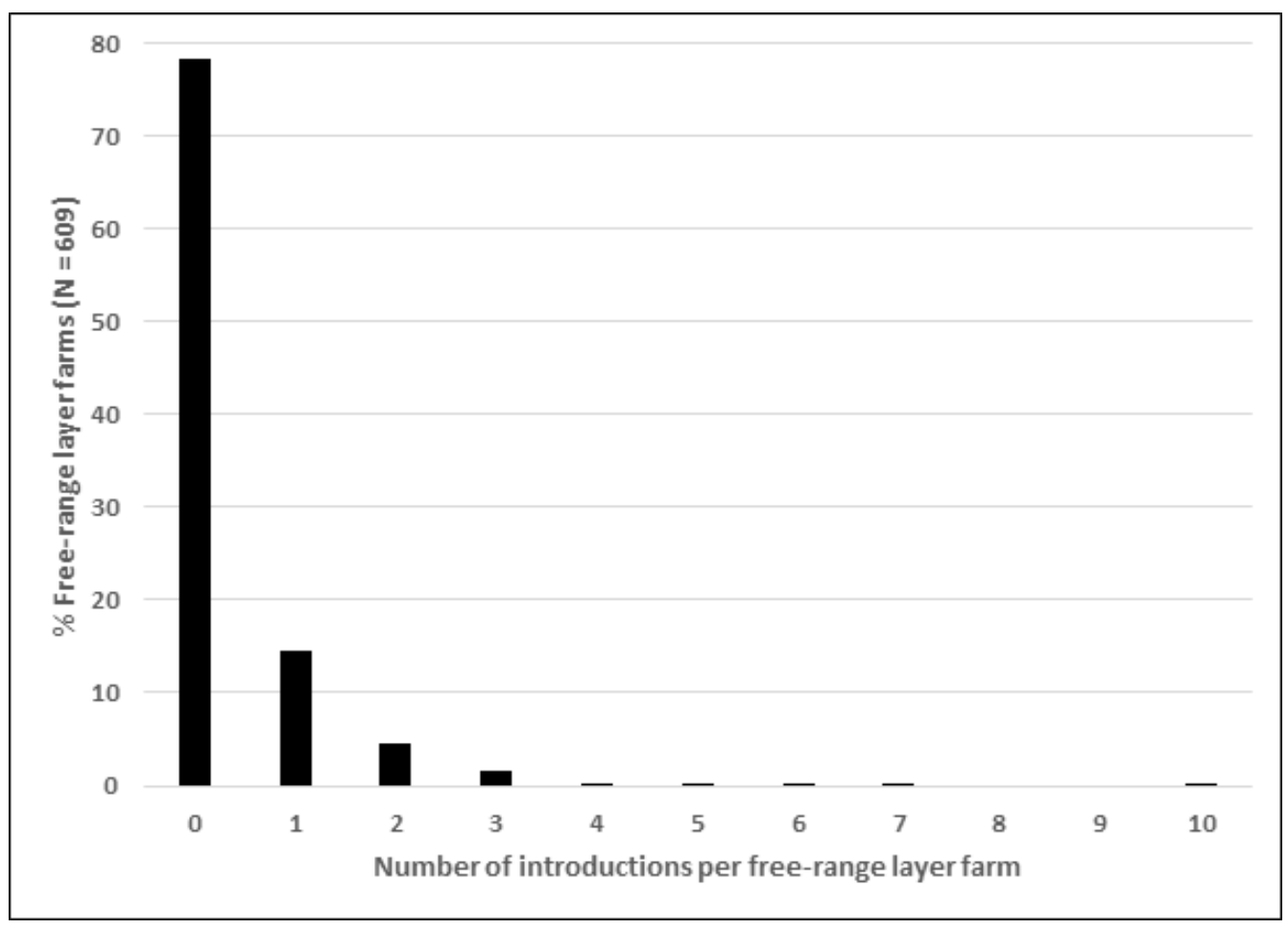

Figure 6

Distribution of low pathogenic avian influenza introductions on free-range layer farms in the Netherlands in the period 20072018. 